\title{
As Melhores Empresas para Trabalhar no Brasil e a Qualidade de Vida no Trabalho: Disjunções entre a Teoria e a Prática
}

\author{
Suzana da Rosa Tolfo \\ Valmíria Carolina Piccinini
}

\section{RESUMO}

$\mathrm{O}$ artigo discute os resultados de pesquisas sobre as melhores empresas para trabalhar no Brasil, divulgadas pela revista Exame nos anos de 1997, 1999 e 2000. Os pesquisadores identificaram as 30, 50 e 100 empresas que ofereceram, nos respectivos anos, as condições mais atraentes para os trabalhadores, com base em dimensões que permitem avaliar as melhores práticas em recursos humanos. Os itens pesquisados apresentam estreita similaridade com o modelo de Walton (1973) de qualidade de vida no trabalho. O método utilizado foi caracterizado como exploratório-descritivo. A análise dos dados demonstra que as organizações cujas práticas foram avaliadas de forma mais positiva pelos seus empregados nos anos de 1997 e 1999 enfatizam, em primeiro lugar, o orgulho do trabalho e da empresa. No ano de 2000 o principal aspecto valorizado foi a oportunidade de carreira e treinamento. No conjunto, observou-se uma redução do número de empresas e de itens em relação aos quais elas receberam a avaliação máxima por parte dos empregados.

Palavras-chaves: qualidade de vida no trabalho; recursos humanos.

\begin{abstract}
The present article discusses the results of surveys about the best companies to work for in Brazil, conducted by Exame magazine in the years 1997, 1999 and 2000. The researchers identified the 30, 50 and 100 companies which offered in the respective years the most attractive working conditions, based on dimensions which allow an evaluation of the best practices in the human resources area. The items investigated present a close resemblance to Walton's (1973) model of quality of working life. The methodology used was characterized as descriptive-exploratory. The data analysis indicates that those organizations whose practices were evaluated positively by their employees in the years 1997 and 1999 propitiated, first of all, a sense of pride in the work and in the company. In the year 2000 the most valued aspects were career opportunities and training. In general terms, we have observed that there has been a reduction in the number of companies which received top grades from their employees, as well as in the number of items positively evaluated.
\end{abstract}

Key words: quality of working life; human resources. 


\section{INTRODUÇÃO}

O mundo do trabalho vem passando por profundas transformações. Temáticas como globalização, flexibilização, competitividade e novas formas de organização do trabalho têm sido destacadas nas análises daqueles que atuam nas organizações ou as estudam. Nesta fase da dita terceira Revolução Industrial, as pessoas que atuam nas organizações passam a ser fonte de interesse: conforme assinalam alguns autores, são os colaboradores que possibilitam a vantagem competitiva nas organizações e faz-se necessária a implementação de ações que propiciem a qualidade de vida no trabalho (QVT). Por outro lado, há articulistas, como Peter Drucker, que sinalizam que a valorização das pessoas no ambiente de trabalho é mais aparente do que real.

Nesse sentido, o presente artigo objetiva contribuir para o debate da questão, ao discutir os principais resultados das pesquisas elaboradas pelo Great Place to Work (Robert Levering), e publicadas na revista Exame (1997, 1999, 2000), que mostram o panorama mais atual das empresas brasileiras que oferecem as condições de trabalho mais atraentes para os seus empregados. Com base nos dados levantados, fez-se uma análise que permitiu estabelecer relações com a teoria referente à qualidade de vida no trabalho e tecer considerações sobre as possíveis disjunções entre a teoria e a prática, no contexto social, político e econômico brasileiro.

Inicialmente será apresentada uma breve revisão teórica acerca da qualidade de vida no trabalho, contemplando aspectos históricos, principais conceitos e o modelo de Walton (1973). Em seqüência, está a descrição da metodologia adotada na pesquisa contemplada no artigo, bem como os critérios adotados para proceder ao presente estudo. Por fim, apresentam-se os resultados e a análise dos dados, seguidos das principais conclusões.

\section{Qualidade de Vida no Trabalho}

Os estudos ligados à qualidade de vida no trabalho foram iniciados nos anos 50 e apresentaram diversas fases. Eric Trist e seus colaboradores do Tavistok Institute, Londres, são apontados como os precursores das pesquisas ligadas à qualidade de vida no trabalho. Na década citada, eles iniciaram uma série de 
estudos que deram origem a uma abordagem sociotécnica em relação à organização do trabalho, com uma preocupação com a satisfação e o bem-estar do trabalhador. No entanto somente na década de 60 é que o movimento tomou impulso, a partir da conscientização da importância de se buscarem melhores formas de organizar o trabalho, com a finalidade de minimizar os seus efeitos negativos sobre o trabalhador e alcançar o seu bem-estar geral.

A primeira fase do movimento estendeu-se até 1974, quando decaiu o interesse pela QVT em função da preocupação com questões econômicas, como a crise energética e a crescente inflação. A necessidade de sobrevivência das empresas fez com que os interesses dos funcionários passassem a ter uma importância secundária.

A partir de 1979, ressurgiu a preocupação com a QVT devido, principalmente, à perda de competitividade das indústrias norte-americanas em face das suas concorrentes japonesas. Esta perda de competitividade levou à investigação dos estilos gerenciais praticados em outros países e a relacionar os programas de produtividade aos esforços com a melhoria da QVT.

No Brasil a preocupação com QVT surge mais tardiamente, também em função da preocupação com a competitividade das empresas, em contexto de maior abertura para a importação de produtos estrangeiros e na esteira dos programas de qualidade total (Fernandes, 1996).

Embora a temática da qualidade de vida no trabalho tenha recebido considerável atenção nestas duas últimas décadas, ainda existe alguma incerteza com relação ao sentido exato do termo.

Através do Quadro 1 é possível compreender como o campo de estudo foi evoluindo, de uma perspectiva mais restrita para outras mais amplas.

O termo genérico qualidade de vida no trabalho engloba aspectos analisados anteriormente como motivação, satisfação, condições de trabalho, estilos de liderança, entre outros. Relacionados a estes aspectos, a lista de fatores que se constituem em pontos positivos e negativos do trabalho é bem ampla.

Em função da diversidade de conceituações para QVT, Fernandes (1996) chama a atenção para a necessidade de aprofundar a revisão da literatura do tema, porque não se pode trabalhar com algo que não se sabe exatamente o que é.

Um dos principais expoentes no estudo da questão, Walton (1973), articula a conceituação que segue: "a idéia de QVT é calcada em humanização do trabalho e responsabilidade social da empresa, envolvendo o entendimento de necessidades e aspirações do indivíduo, através da reestruturação do desenho de cargos e 
novas formas de organizar o trabalho, aliado a uma formação de equipes de trabalho com maior poder de autonomia e melhoria do meio organizacional".

\section{Quadro l: Evolução do Conceito de QVT}

\begin{tabular}{|l|l|}
\hline \multicolumn{2}{|c|}{ EVOLUÇÃO DO CONCEITO DE QVT } \\
\hline $\begin{array}{l}\text { CONCEPC̃̃ES EVOLUTIVAS } \\
\text { DA QVT }\end{array}$ & \multicolumn{1}{|c|}{ CARACTERÍSTICAS OU VISÃO } \\
\hline $\begin{array}{l}\text { 1 - QVT como uma variável } \\
\text { (1959 a 1972) }\end{array}$ & $\begin{array}{l}\text { Reação do indivíduo ao trabalho. Era investigado como melhorar a } \\
\text { qualidade de vida no trabalho para o indivíduo. }\end{array}$ \\
\hline $\begin{array}{l}\text { 2 - QVT como uma abordagem } \\
\text { (1969 a 1974) }\end{array}$ & $\begin{array}{l}\text { O foco era o indivíduo antes do resultado organizacional; mas, ao mesmo } \\
\text { tempo, tendia a trazer melhorias tanto ao empregado como à direção. }\end{array}$ \\
\hline $\begin{array}{l}\text { 3 - QVT como um método } \\
\text { (1972 a 1975) }\end{array}$ & $\begin{array}{l}\text { Um conjunto de abordagens, métodos ou técnicas para melhorar o } \\
\text { ambiente de trabalho e tornar o trabalho mais produtivo e mais satisfatório. } \\
\text { QVT era vista como sinônimo de grupos autonomos de trabalho, } \\
\text { enriquecimento de cargo ou desenho de novas plantas com integração } \\
\text { social e técnica. }\end{array}$ \\
\hline $\begin{array}{l}\text { 4 - QVT como um movimento } \\
\text { (1975 a 1980) }\end{array}$ & $\begin{array}{l}\text { Declaração ideológica sobre a natureza do trabalho e as relações dos } \\
\text { trabalhadores com a organização. Os termos administração participativa } \\
\text { e democracia industrial eram freqüentemente ditos como idéias do } \\
\text { movimento de QVT. }\end{array}$ \\
\hline $\begin{array}{l}\text { 5 - QVT como tudo } \\
\text { (1979 a 1982) }\end{array}$ & $\begin{array}{l}\text { Como panacéia contra a competição estrangeira, problemas de qualidade, } \\
\text { baixas taxas de produtividade, problemas de queixas e outros problemas } \\
\text { organizacionais. }\end{array}$ \\
\hline 6 - QVT como nada (futuro) & $\begin{array}{l}\text { No caso de alguns projetos de QVT fracassarem no futuro, não passará } \\
\text { de apenas um modismo passageiro. }\end{array}$ \\
\hline
\end{tabular}

Fonte: Nadler e Lawler, (apud Fernandes, 1996, p. 42).

Bowditch e Buono (1992) enfatizaram as práticas adotadas pelas organizações e que se constituem em ações voltadas à QVT. Para estes autores,

"um conjunto de definições equaciona a QVT com a existência de um certo conjunto de condições e práticas organizacionais tais como cargos enriquecidos, participação dos empregados nos processos de tomada de decisões, condições seguras de trabalho e assim por diante. Uma outra abordagem equaciona a QVT com os efeitos visíveis que as condições de trabalho têm no bem-estar de um indivíduo (por exemplo, manifestação de satisfação no local de trabalho, crescimento e desenvolvimento dos funcionários, a capacidade de atender a toda a gama de necessidades humanas)" (Bowditch e Buono, 1992, p. 207).

Ao tratar especificamente do caso brasileiro, Hanashiro e Vieira (apud Fernandes e Becker, 1988) chamam a atenção para a necessidade de se ter uma visão situacional de QVT, partindo de um contexto sócio-econômico e político local, que é totalmente diferente dos países desenvolvidos; por isso, para as autoras, $\mathrm{o}$ conceito de qualidade de vida no trabalho é amplo, flexível e contingencial. 


\section{Modelo de Walton para QVT}

Existem diversos métodos que foram desenvolvidos por estudiosos, visando a identificar os aspectos presentes no trabalho e que estão relacionados à qualidade de vida no trabalho. O modelo proposto por Walton (1973) será o referencial básico para se analisar as práticas adotadas nas melhores empresas para trabalhar no Brasil e as dimensões de QVT, em razão da sua amplitude.

As dimensões e os seus respectivos indicadores de QVT apresentados por Walton (1973) são os seguintes:

- Compensação justa e adequada: eqüidade salarial interna, eqüidade salarial externa e benefícios.

- Condições de trabalho: condições físicas seguras e salutares e jornada de trabalho.

. Oportunidade de uso e desenvolvimento das capacidades: autonomia e possibilidades de autocontrole, aplicação de habilidades variadas e perspectivas sobre o processo total do trabalho.

. Oportunidade de crescimento contínuo e segurança: oportunidade de desenvolver carreira e segurança no emprego.

. Integração social no trabalho: apoio dos grupos primários, igualitarismo e ausência de preconceitos.

- Constitucionalismo: normas e regras, respeito à privacidade pessoal e adesão a padrões de igualdade.

- Trabalho e o espaço total da vida: relação do papel do trabalho dentro dos outros níveis de vida do empregado.

. Relevância social da vida no trabalho: relevância do papel da organização em face do ambiente.

As oito dimensões inter-relacionadas formam um conjunto que possibilita ao pesquisador apreender os pontos percebidos pelos trabalhadores como positivos ou negativos na sua situação de trabalho. Apresentam a vantagem de analisar tanto o conjunto de condições e práticas organizacionais, como aspectos relacionados à satisfação e percepção dos empregados sobre os fatores positivos no trabalho (Silva e Tolfo, 1995).

A forma como as empresas efetivamente concebem a QVT pode ser mais bem verificada nas práticas de recursos humanos que adotam. Ao analisar as 
principais características das novas políticas de recursos humanos em contexto de competitividade acirrada, Albuquerque e França (1998) citam as seguintes:

. recompensas econômicas conjugadas com recompensas simbólicas;

- substituição dos mecanismos clássicos de controle pela confiança;

. substituição de linguagem, preconizando-se colaboradores, parceiros, portas abertas etc.;

. espírito global, isto é, empresa algo mais do que local de trabalho;

. oportunidade de promoções horizontais e verticais;

. estabilidade de emprego;

. autonomia controlada;

. competição acentuada no mercado;

. competição no interior da empresa, isto é, duelos de desempenho;

. controle via autodisciplina, pressão, autonomia outorgada, valorização do trabalho;

. medidas para aumentar fluxos de informações;

. intelectualização das tarefas;

. grande exigência de flexibilidade e adaptabilidade;

. tendência a eliminar o papel autoritário da hierarquia;

. valorização do consenso, antecipação dos conflitos;

. política de individualização, visando a evitar reivindicações coletivas;

. controle por adesão e interiorização de regras;

- redução drástica do número de especialistas;

. novas formas de gerenciamento científico das pessoas;

. educação como ênfase à educação profissional;

- síntese dos modelos japonês (equipe) e americano (esforço individual);

. existência do outro, isto é, visando à impressão de respeito e valorização do próximo; 
. exigência de QT - defeito zero - dos produtos e serviços;

. substituição da programação pela estratégia;

. priorização dos objetivos financeiros.

No transcurso do artigo, procura-se analisar as tendências de políticas de recursos humanos que caracterizam as empresas top para se trabalhar no Brasil.

\section{Metodologia Adotada pelas Pesquisas em Análise}

As melhores empresas para nelas se trabalhar no Brasil foram divulgadas pela revista Exame nos três anos especificados ${ }^{(1)}$. A base para análise foi a avaliação do conjunto das políticas de recursos humanos adotadas, que configura o melhor desempenho no que se refere a salários, benefícios, clima de trabalho estimulante, perspectivas de desenvolvimento na carreira, possibilidade de desenvolvimento e realização profissional.

Os procedimentos adotados envolveram o seguinte elenco:

. Convite às empresas para participação na pesquisa (1997) ou inscrição delas (1999 e 2000);

. Envio de questionários às empresas selecionadas, sendo um destinado ao pessoal de recursos humanos e outro para ser respondido por funcionários escolhidos aleatoriamente;

. Processamento dos resultados e elaboração de short list das empresas que obtiveram pontuações mais altas.

. Encaminhamento de questionário às empresas constantes no short list, investigando políticas formais de recursos humanos quanto ao seguinte: salários e benefícios, oportunidades de carreira, clareza e abertura na comunicação entre funcionários e chefias, segurança e confiança na gestão, orgulho do trabalho e da empresa, camaradagem no ambiente de trabalho, treinamento e desenvolvimento e inovação no sistema de trabalho. Os itens foram avaliados com base em notas e pesos.

. Classificação das empresas com melhores resultados, com base nos questionários respondidos.

. Entrevistas com empregados e chefias, separadamente, das empresas selecio- 
nadas e, posterior listagem das 30, 50 e 100 empresas consideradas as melhores para nelas se trabalhar, nos anos de 1997, 1999 e 2000 respectivamente.

Com vistas a analisar os dados, apresentam-se os resultados das empresas mais bem colocadas em relação aos itens considerados pelos pesquisadores ${ }^{(2)}$ como aqueles essenciais para que uma empresa possa ser considerada excelente lugar para nela se trabalhar. Os 8 itens avaliados em 1997 foram: salários e benefícios, oportunidades de carreira, clareza e abertura na comunicação entre funcionários e chefias, segurança e confiança na gestão, orgulho do trabalho e da empresa, camaradagem no ambiente de trabalho, treinamento e desenvolvimento e inovação no sistema de trabalho.

Em 1999 o primeiro item foi desdobrado em dois, considerando separadamente salários e benefícios. Para cada um deles, foi definida uma escala de 1 a 5, em ordem crescente, que, no seu conjunto, possibilitam inferir a qualidade de vida no trabalho do capital humano em empresas brasileiras. A alteração no ano 2000 foi a análise de 8 itens, sendo que oportunidade de carreira e treinamento passaram a formar um só, assim como a inovação no sistema de trabalho foi substituída pelo quesito responsabilidade social. Certamente que essas alterações apresentam reflexos sobre a análise dos três anos que o artigo abrange; entretanto considera-se que esta pode ser efetuada sem que se percam os objetivos principais de acompanhar as tendências que as empresas vêm adotando, em termos de políticas de recursos humanos e indicadores de qualidade de vida.

Foram selecionadas como objeto do presente estudo aquelas empresas que obtiveram avaliação máxima em pelo menos 4 dos itens que caracterizam uma organização excelente para nela se trabalhar.

\section{Os Resultados}

Levando-se em consideração que o número de empresas selecionadas (30, 50 e 100) e as características que as tornam as melhores empresas para nelas se trabalhar no Brasil, optou-se por apresentar e analisar os resultados mais relevantes das empresas, com avaliação mais positiva, em ordem decrescente. Para tanto, consideraram-se as avaliações na escala de 1 a 5, em relação aos oito itens anteriormente apresentados. A seguir serão contemplados os principais resultados, apresentando-se inicialmente os referentes ao ano de 1997.

A empresa que apresentou o melhor resultado foi a Fiat, com avaliações máximas em relação à oportunidade de carreira, segurança e confiança na gestão, 
orgulho do trabalho e da empresa, clareza e abertura na comunicação interna, camaradagem no ambiente de trabalho e treinamento e desenvolvimento.

$\mathrm{Na}$ avaliação da maior vantagem da empresa, foi citada uma série de medidas simpáticas que conquistam o funcionário e a sua família. Incluem a vinda do número 1 da hierarquia na Itália ao Brasil para entregar prêmios pelo desempenho acadêmico de filhos de funcionários, o programa Vida Nova para orientação no pré-natal, até presentes no nascimento, colônia de férias para filhos dos empregados, megaclube, Domingo na Fiat, e outras demonstrações que, segundo a revista Exame, são consideradas pelos diretores de recursos humanos como paternalismo explícito.

Como principais atrativos estão arrolados o plano de saúde com cobertura total, o patrocínio de cursos superiores e de pós-graduação em áreas de interesse da empresa, o subsídio para o estudo dos filhos de funcionários, o direito dos funcionários de indicarem pessoas para o processo de seleção, o desconto para a compra de carros.

As empresas que apresentaram avaliações com valor máximo (5) em relação a cinco dos itens considerados, foram as seguintes:

(1) Accor Brasil

(2) Arthur Andersen

(3) PROMON

(4) Samarco
- Segurança e confiança na gestão

- Orgulho do trabalho e da empresa

- Clareza e abertura na comunicação interna

- Camaradagem no ambiente de trabalho

. Inovação no sistema de trabalho

- Oportunidade de carreira

- Segurança e confiança na gestão

- Orgulho do trabalho e da empresa

- Clareza e abertura na comunicação interna

. Treinamento e desenvolvimento

. Salários e benefícios

- Segurança e confiança na gestão

. Orgulho do trabalho e da empresa

- Clareza e abertura na comunicação interna

. Inovação no sistema de trabalho

- Oportunidade de carreira

- Segurança e confiança na gestão

. Orgulho do trabalho e da empresa 
- Clareza e abertura na comunicação interna

. Camaradagem no ambiente de trabalho

(5) USIMINAS

- Oportunidade de carreira

. Salários e benefícios

- Segurança e confiança na gestão

- Orgulho do trabalho e da empresa

. Camaradagem no ambiente de trabalho

As organizações com melhores resultados (5) em relação a quatro dos itens considerados, foram as seguintes (Exame, 1997):

(6) Belgo Mineira

. Oportunidade de carreira

. Orgulho do trabalho e da empresa

- Clareza e abertura na comunicação interna

. Inovação no sistema de trabalho

(7) BRASMOTOR

- Oportunidade de carreira

- Orgulho do trabalho e da empresa

- Clareza e abertura na comunicação interna

. Camaradagem no ambiente de trabalho

(8) Elma Chips

- Segurança e confiança na gestão

- Orgulho do trabalho e da empresa

- Clareza e abertura na comunicação interna

. Camaradagem no ambiente de trabalho

(9) Good Year

- Oportunidade de carreira

- Orgulho do trabalho e da empresa

- Camaradagem no ambiente de trabalho

. Treinamento e desenvolvimento

(10) Xerox

. Oportunidade de carreira

- Segurança e confiança na gestão

. Orgulho do trabalho e da empresa

. Clareza e abertura na comunicação interna

Pelos resultados apresentados, é possível verificar que as empresas avaliadas como melhores locais para nelas se trabalhar no ano de 1997 proporcionaram aos seus funcionários: 
. Orgulho do trabalho e da empresa.

. Clareza e abertura na comunicação interna.

. Oportunidade de carreira.

- Camaradagem no ambiente de trabalho.

. Segurança e confiança na gestão.

. Treinamento e desenvolvimento.

. Inovação no sistema de trabalho.

. Salários e benefícios.

Entre as principais vantagens de cada uma das organizações citadas anteriormente, seguindo a ordem de apresentação, tem-se este decálogo:

. Sistema de gestão descentralizado e que proporciona autonomia.

. Possibilidade de o funcionário tornar-se sócio.

. Os empregados são os donos da empresa (comunidade de profissionais).

. Ampla oportunidade de ascensão profissional.

. Emprego estável.

. Sistema de premiação de resultados.

. Excelente sistema de remuneração.

. Ambiente de trabalho alegre e descontraído.

. Exportação de talentos para outras subsidiárias do mundo.

. Ambiente de trabalho agradável e comunicação aberta.

No ano de 1999, verificam-se mudanças nas avaliações a que as empresas foram expostas, se comparado com 1997. As empresas foram avaliadas em relação a nove itens, e somente uma delas recebeu avaliação máxima (5) em relação a seis quesitos. A Renner se diferenciou por proporcionar segurança e confiança na gestão, orgulho do trabalho e da empresa, clareza e abertura na comunicação interna, camaradagem no ambiente de trabalho, treinamento e desenvolvimento e inovação no sistema de trabalho.

O principal diferencial da Renner é a autonomia concedida aos funcionários. Eles devem ser liberados para criar, criticar e questionar. A distribuição de poder fez com que os empregados passassem a se empenhar cada vez mais para satis- 
fazer os clientes e esperam que o bom atendimento reverta em propaganda bocaa-boca para ampliar a clientela.

Os principais atrativos que fazem com que a Renner tenha sido considerada a empresa que oferece as melhores condições para o trabalho são: ampla comunicação sobre a situação da empresa e aspectos que impactam nos empregados; premiação mensal dos melhores vendedores; metas individuais de vendas associadas a comissões compartilhadas igualmente pelo grupo; avaliações trimestrais e feedback face a face com a chefia; e a preocupação de que as demissões sejam justas.

Enquanto no ano de 1977 havia cinco empresas que receberam pontuação máxima para cinco itens, no ano de 1999 somente duas apresentaram o mesmo resultado, conforme se verifica na seqüência.

(1) Hewlett Packard

(2) PROMON
. Salários.

. Benefícios.

. Oportunidade de carreira.

. Segurança e confiança na gestão.

. Treinamento.

- Salários.

- Benefícios.

. Segurança e confiança na gestão.

. Orgulho do trabalho e da empresa.

. Treinamento.

Os melhores desempenhos em relação a quatro dos itens analisados foram alcançados pelas seguintes empresas (Exame, 1999):

(3) $\mathrm{ABB}$

(4) Accor
- Oportunidade de carreira.

- Orgulho do trabalho e da empresa.

. Camaradagem no ambiente de trabalho.

. Inovação no sistema de trabalho.

- Oportunidade de carreira.

- Segurança e confiança na gestão.

- Treinamento e desenvolvimento.

. Inovação no sistema de trabalho. 
(5) Dpascoal

(6) Du Pont

(7) Good Year

(8) Lucent Technologies

(9) Magazine Luiza

(10) McDonald's

(11) Merck Sharp e Dohme

(12) Meritor
- Salários.

- Segurança e confiança na gestão.

. Orgulho do trabalho e da empresa.

- Clareza e abertura na comunicação interna.

. Benefícios.

. Oportunidade de carreira.

- Orgulho do trabalho e da empresa.

. Inovação no sistema de trabalho.

. Benefícios.

. Oportunidade de carreira.

- Orgulho do trabalho e da empresa.

. Camaradagem no ambiente de trabalho.

. Salários.

- Oportunidade de carreira.

- Segurança e confiança na gestão.

. Orgulho do trabalho e da empresa.

- Segurança e confiança na gestão.

- Orgulho do trabalho e da empresa.

- Clareza e abertura na comunicação interna.

. Treinamento e desenvolvimento.

- Segurança e confiança na gestão.

- Orgulho do trabalho e da empresa.

- Clareza e abertura na comunicação interna.

. Camaradagem no ambiente de trabalho.

- Salários.

- Segurança e confiança na gestão.

. Orgulho do trabalho e da empresa.

. Camaradagem no ambiente de trabalho.

- Oportunidade de carreira.

- Orgulho do trabalho e da empresa.

- Camaradagem no ambiente de trabalho.

. Inovação no sistema de trabalho. 
(13) Microsiga

(14) Redecard

(15) Samarco

(16) Union Carbide
- Oportunidade de carreira.

- Clareza e abertura na comunicação interna.

. Treinamento e desenvolvimento.

. Inovação no sistema de trabalho.

- Segurança e confiança na gestão.

- Orgulho do trabalho e da empresa.

- Clareza e abertura na comunicação interna.

. Camaradagem no ambiente de trabalho.

. Benefícios.

. Segurança e confiança na gestão.

. Orgulho do trabalho e da empresa.

. Treinamento e desenvolvimento.

. Benefícios.

- Oportunidade de carreira.

- Camaradagem no ambiente de trabalho.

. Inovação no sistema de trabalho.

Ao se considerar o conjunto dos resultados, constata-se que os empregados avaliam como mais contemplados os seguintes indicadores que se referem à qualidade de vida no trabalho, em ordem decrescente:

. Orgulho do trabalho e da empresa.

. Segurança e confiança na gestão.

. Oportunidade de carreira.

. Camaradagem no ambiente de trabalho.

. Treinamento.

. Inovação no sistema de trabalho.

. Benefícios.

. Clareza e abertura na comunicação interna.

. Salários.

As principais vantagens apresentadas por essas empresas mais bem avaliadas pelos empregados formam o seguinte rol: 
. Salários no topo do mercado e distribuição de stock options a todos os empregados.

. Possibilidade de o funcionário tornar-se sócio ( $85 \%$ dos empregados são).

. Ótimo ambiente de trabalho e propício à aprendizagem.

. Treinamento a todos pela Universidade Accor.

. Preocupação com a saúde física e financeira dos empregados.

. Valorização e incentivo à lealdade.

. Possibilidades amplas de carreira.

. Informalidade e proximidade entre chefes e empregados.

. Carreira com base na meritocracia.

. Ótimo clima de trabalho.

. Oportunidades de crescimento profissional para os empregados.

. Premiação ilimitada em caso de superação das metas.

. Comunicação excelente entre funcionários e gestão.

. Financiamento da casa própria em ótimas condições.

- Alto grau de autonomia dos empregados.

No ano 2000 a Fiat foi novamente considerada como a melhor empresa para nela se trabalhar no Brasil, como em 1997. Recebeu nota máxima em relação a seis itens: salários, benefícios, oportunidade de carreira e treinamento, segurança e confiança na gestão, camaradagem no ambiente de trabalho e responsabilidade social.

A maior vantagem da empresa, identificada na revista Exame (2000), é a inexistência de qualquer espécie de reclamação por parte dos empregados, mesmo no atinente a salários. Os principais atrativos são atribuídos a programas como estes: empregados antenas que recebem informações privilegiadas da cúpula $\mathrm{e}$ repassam aos colegas; Boas Idéias e Soluções (BIS) para apresentar sugestões; reunião anual de 1.200 empregados com o presidente para socializar resultados e objetivos do próximo ano; reconhecimento obrigatório do trabalho dos empregados pelas chefias, por prêmios ou cartas; e participação nos resultados. A empresa é descrita como a própria casa e alguns empregados afirmam que se trata de uma grande família. Há um clube que congrega as famílias em diversas ativida- 
des, reiterando indicativos apresentados em 1997 sobre um estilo paternalista de administrar.

Embora outros indicadores, turnover, por exemplo, o desloquem do topo, o McDonald's também recebeu avaliação 5 em relação a seis itens avaliados. São eles: salários, benefícios, oportunidade de carreira e treinamento, segurança e confiança na gestão, orgulho do trabalho e da empresa, clareza e abertura na comunicação.

O diferencial da empresa em relação às demais está nas possibilidades de crescimento, desde a base. Os empregados são atraídos pela possibilidade do primeiro emprego, pela premiação aos melhores desempenhos, individual e por grupo de trabalho, pelo direito ao sabático para gerentes e diretores, pela responsabilidade social (McLanche Feliz) e pelo expediente reduzido nas sextas-feiras, entre o Natal e o Carnaval.

Somente uma empresa alcançou a pontuação máxima em relação a cinco itens avaliados, como se vê a seguir (Exame, 2000).

(1) Arvin Meritor

. Salários.

. Benefícios.

- Oportunidade de carreira e treinamento.

. Segurança e confiança na gestão.

. Orgulho do trabalho e da empresa.

As empresas que receberam avaliação 5 em quatro itens foram as seguintes:

(2) Hewlett Packard

(3) $\mathrm{ABB}$

(4) Xerox
. Benefícios.

- Oportunidades de carreira e treinamento.

. Segurança e confiança na gestão.

. Responsabilidade social.

- Salários.

- Oportunidades de carreira e treinamento.

. Orgulho do trabalho e da empresa.

. Responsabilidade social.

- Oportunidades de carreira e treinamento.

- Segurança e confiança na gestão.

- Orgulho do trabalho e da empresa.

- Clareza e abertura na comunicação interna. 
No ano 2000 as melhores empresas apresentam os seguintes aspectos relacionados à qualidade de vida dos empregados, em ordem de importância:

. Oportunidade de carreira e treinamento.

- Segurança e confiança na gestão.

. Orgulho do trabalho e da empresa.

- Salários.

- Benefícios.

. Responsabilidade social.

- Clareza e abertura na comunicação interna.

As principais vantagens associadas a cada uma das empresas citadas compõem este rol:

. Investimento elevado em qualificação.

. Pessoas são o centro do negócio.

. Ótimo programa de qualidade de vida.

. Excelente ambiente de trabalho.

Após essa sistematização final, os dados são analisados à luz do referencial teórico sobre qualidade de vida no trabalho (Walton, 1973).

\section{Análise dos Dados com Base na Teoria sobre QVT}

A análise inicia-se com aqueles dados relativos às melhores empresas para nelas se trabalhar no ano de 1997.

O item identificado como mais representativo das melhores empresas para nelas se trabalhar é o orgulho do trabalho e da empresa. Articulando-se com o modelo de Walton (1973) para a análise da qualidade de vida no trabalho, percebe-se que ele está relacionado com a relevância social da vida no trabalho. Isso quer dizer que os funcionários avaliam como positiva a imagem da empresa decorrente da sua atuação perante a sociedade.

Pode inferir-se que os empregados das empresas consideradas excelentes lugares para nelas se trabalhar percebem que esta possibilidade é decorrente, em primeiro lugar, de um aspecto mais amplo, que é o papel social do trabalho e da empresa. Tal resultado chama a atenção para duas hipóteses mais imediatas: 
- Seria em decorrência do desenvolvimento de uma perspectiva mais sistêmica no interior das organizações;

. Ou isso se deve à impossibilidade de conquistar resultados mais objetivos em face do conflito na relação capital-trabalho.

Por seu lado, a literatura recente traz diversos trabalhos que tratam do comprometimento no trabalho. Existe preocupação em aferir em que grau isso ocorre, as principais redes de comprometimento, em relação ao sindicato, ao grupo de formação, à empresa, e os seus impactos sobre o ambiente de trabalho. Bastos (1997) tem desenvolvido uma série de estudos em parceria com colaboradores; em um deles salienta o seguinte:

“a noção de 'Mudanças Organizacionais' é quase de senso comum hoje em dia, tal é o grau de disseminação dos programas que visam estabelecer novas perspectivas para as organizações no contexto complexo e mutável da sociedade contemporânea. Quer sejam definidas como 'Programas de Qualidade', 'Reengenharia' ou mesmo 'Desenvolvimento Organizacional', subjacente a estes processos há a expectativa de que as transformações na estrutura e dinâmica da organização levem a níveis mais elevados de comprometimento com o trabalho".

Em síntese, o comprometimento organizacional é representativo do vínculo do indivíduo com o seu trabalho e com a organização empregadora. Tem representado para a teoria administrativa atual um instrumento de colaboração na tentativa de que o empregado vista a camisa da empresa, conforme o ditado que se popularizou.

A clareza e a abertura na comunicação interna foi o segundo elemento que sinalizou excelência para trabalhar. $\mathrm{O}$ processo de comunicação está relacionado ao fator de QVT denominado constitucionalismo e compreende, entre outros, a liberdade de expressão.

A comunicação adquiriu relevância diferenciada com a reestruturação produtiva, uma vez que todo o processo de trabalho deve ocorrer de forma mais ágil, atendendo à velocidade das mudanças que se impõem às organizações. Ao invés das informações grandemente filtradas que predominavam nos moldes do taylorismo, faz-se necessário que as ações se tornem cada vez mais comuns, de modo que sugestões, críticas e conflitos sejam aproveitados pela organização, para melhorar a qualidade dos seus produtos e serviços, e aumentar a produtividade e atender adequadamente a clientela.

A oportunidade de carreira tem o seu correlato no modelo de Walton (1973) de qualidade de vida no trabalho, no fator denominado possibilidade de cresci- 
mento e segurança. Essa é questão importante, porque os empregados a valorizam como um dos itens mais primordiais para que uma organização seja excelente para nela se trabalhar. Por outro lado, existe farta literatura atualizada que sinaliza o fim do emprego e o fim da carreira (Bridges, 1995; Bertoni, 1995; Tomei apud Davel e Vasconcelos, 1996). Pelo que os resultados demonstram, torna-se possível inferir que existe aí um ponto de divergência entre aquilo que os empregados esperam das organizações e o que deverá ser cada vez mais a perspectiva de um tipo de carreira mais horizontalizada, em relação ao modelo hegemônico vigente até pouco tempo atrás.

A integração social na empresa, constante no modelo de QVT, encontra referência no item camaradagem no ambiente de trabalho, investigado na presente análise. A avaliação positiva em relação a tal item vai ao encontro de uma perspectiva atual que valoriza a atuação em times, e em ambiente de trabalho agradável e descontraído, onde predomina a comunicação aberta, tal qual nos exemplos citados na pesquisa, uma das principais vantagens de empresas como a Elma Chips e a Xerox.

A segurança e a confiança na gestão, assinalada pelos empregados das empresas, articula-se com a integração social na empresa e com a oportunidade de segurança. Refere-se a igualdade de oportunidades, relacionamento interpessoal e senso comunitário e sentimento de segurança no emprego.

Em tempos de novas formas de organização do trabalho, tem-se evidenciado a importância de que qualquer mudança que vá ocorrer em uma organização conte com o total comprometimento da gestão, porque, como assinalam os principais articuladores da gestão da qualidade total, o exemplo deve vir de cima.

Em sexta posição, encontram-se as iniciativas de treinamento e desenvolvimento ensejadas pelas empresas, e que encontram correlato no fator de QVT denominado por Walton (1973) de chance de crescimento e segurança, contemplado especificamente na dimensão referente ao crescimento profissional.

A questão da qualificação dos empregados vem sendo amplamente debatida no meio acadêmico e técnico, como ponto central para fazer frente à Terceira Revolução Industrial, que trouxe uma nova era baseada na microeletrônica.

No Brasil a temática é especialmente relevante e preocupante, uma vez que as empresas não têm tradição de investir de modo significativo em treinamento. Isso é verificado, mais uma vez, pelo próprio resultado desta pesquisa, dado que a capacitação para o trabalho não se encontra entre os primeiros itens avaliados positivamente pelos trabalhadores. Isso é justificável, pois uma empresa top em treinamento deve oferecer um mínimo de 80 horas de atividades por ano para 
cada funcionário, enquanto os dados da pesquisa demonstram que somente seis excedem esse patamar e a média de horas das trinta empresas é 56h21 de aula. Muitas delas estão começando a proporcionar cursos de $1^{\circ}$ e $2^{\circ}$ grau, uma vez que automação e flexibilização não são exeqüíveis com operários com uma média de escolaridade de 4 anos, enquanto os nossos vizinhos argentinos têm uma média de 9 anos, e os chineses 13 anos.

A inovação no sistema de trabalho não apresenta um fator ou dimensão no modelo de QVT adotado que possa contemplá-la adequadamente. Por outro lado, chama a atenção o fato de que os empregados considerem a inovação como um dos últimos itens encontrados nas suas organizações e que contribuem para que uma organização seja considerada excelente para trabalhar. Ao que parece as transformações no mundo do trabalho, mais especificamente as inovações, não têm sido associadas a melhorias na qualidade de vida no trabalho.

Ao abordarem a qualidade total, Hackman e Wageman (1995) também contemplam as suas implicações com os aspectos comportamentais. Salientam a importância de alguns processos que são chaves para compreender as pessoas no trabalho, como os seguintes: motivação, isto é, motivação intrínseca, significado do trabalho, foco no alcance de metas e pagamento por desempenho; aprendizagem, advinda da outra pessoa sobre os processos de trabalho e sobre as metas coletivas; e a mudança no processamento de informações e engajamento emocional. Os autores identificam algumas similaridades entre princípios adotados pela qualidade total e pelo movimento pela qualidade de vida no trabalho, mas apresentam também dilemas decorrentes de demandas contraditórias, entre aspectos que incrementariam o comprometimento dos empregados com o trabalho e outros que gerariam insatisfação. Considera-se que tais contradições contribuem de modo categórico para a atitude em relação à TQM; as organizações necessitam suplantá-las para alcançar os seus objetivos.

Os salários e benefícios aparecem como os itens menos contemplados pelas empresas mais bem avaliadas como um lugar excelente para nelas se trabalhar no Brasil. Este item pode ser relacionado ao fator descrito por Walton (1973) como compensação justa e adequada, e compreende a renda adequada ao trabalho, a eqüidade interna e a eqüidade externa.

Tal questão é amplamente conhecida e pode ser analisada sob diversas variantes. Se a origem for nos estudos da psicologia, tem-se em Herzberg uma contribuição ainda hoje importante, quando assinala que o salário tem uma função higiênica sobre a motivação. A remuneração e os benefícios não funcionam como fonte de motivação, mas servem unicamente para evitar a desmotivação. Com base em indicadores econômicos e sociológicos, torna-se possível contrastar o salário mínimo brasileiro com o dos demais países da própria América Latina, 
para constatar o quanto ele é baixo. Segundo Ruas (1994, p. 98), a partir da década de 80 , houve uma "redução dos salários reais na maioria dos setores", como decorrência dos impactos da reestruturação sobre o mercado de trabalho.

O atual contexto do trabalho coloca os capitalistas em situação plenamente favorável quanto à definição das bases salariais. Há elevado contingente de trabalhadores que se encontra excluído do mercado formal de trabalho e que não consegue retornar a ele. Isso faz com que aqueles que são empregados se sujeitem à redução de salário ou outras condições que impliquem perdas, uma vez que as condições existentes passam a ser avaliadas como melhores do que o desemprego. A adoção de estratégias de recursos humanos, tal qual a remuneração por competências, também contribui para que a negociação coletiva seja suplantada por outras formas, como a remuneração variável, que privilegia as negociações individualizadas.

Quando se verificam os resultados referentes ao ano de 1999, encontra-se como item mais representativo das melhores empresas para nelas se trabalhar no Brasil o orgulho do trabalho e da empresa. Desse modo, reiteram-se os resultados referentes ao ano de 1997.

A segurança e confiança na gestão passou a ser o segundo aspecto valorizado pelos empregados na última pesquisa. Levando-se em consideração que se encontrava na quinta posição em 1997, pode inferir-se que as chefias absorveram melhor os conceitos introduzidos com as novas formas de organização do trabalho e que lhes prescrevem um papel de articuladoras de equipes, com vistas ao alcance dos objetivos organizacionais.

A oportunidade de carreira permanece como o terceiro item que caracteriza as empresas avaliadas como excelentes locais para trabalhar. Desse modo reitera-se que, apesar dos paradoxos que cercam a questão, os empregados permanecem valorizando as oportunidades de promoção. A camaradagem no ambiente de trabalho também se encontra na mesma posição, o que sinaliza que, embora seja encontrada, não está entre os itens mais motivadores nas empresas.

O treinamento e a inovação no sistema de trabalho foram igualmente valorizados, recebendo maior destaque do que na pesquisa de 1997. Isso mostrase plenamente justificável, quando se considera que as empresas estão cada dia mais preocupadas com a qualificação, com o desenvolvimento de competências e com as inovações para dar suporte às suas necessidades de vantagem competitiva.

Em 1999, a clareza e abertura na comunicação apareceu em penúltimo lugar como característica das empresas avaliadas, contrastando com os resultados da primeira pesquisa. Considerando-se a importância da comunicação para a 
gestão dos processos organizacionais, há que se questionar se estaria caracterizando-se um paradoxo, em que as relações próximas de chefia-subordinado estão marcadas pela confiança, ao passo que os empregados estariam sendo alijados na comunicação mais ampla, isto é, das estratégias empresariais. Os benefícios também se encontram na mesma posição, o que indica que as empresas não têm privilegiado aspectos relativos à compensação justa e adequada pelo trabalho realizado. Essa tese é reiterada, quando se verifica que os salários permanecem na última posição nos anos de 1997 e 1999, denotando que as melhores empresas para nelas se trabalhar não privilegiam reforços monetários.

No ano 2000 observa-se que há uma mudança efetiva em relação aos aspectos mais valorizados pelos empregados como aqueles existentes nas empresas e que as tornam bons lugares de trabalho. Nos dois anos analisados anteriormente, $o$ orgulho do trabalho e da empresa se mantinha como principal aspecto encontrado nas empresas top, a oportunidade de carreira e a camaradagem no ambiente de trabalho permaneciam na mesma posição, enquanto os salários eram o aspecto mais limitado da excelência no tratamento dos funcionários. No contexto atual verificou-se uma ascensão do aspecto carreira, liderando os itens encontrados nas empresas e valorizados pelos empregados.

A segurança e confiança na gestão permaneceu com o mesmo grau de importância em face dos demais resultados, reforçando as inferências anteriores. Em seqüência encontram-se avaliados com os mesmos resultados o orgulho do trabalho e da empresa, os salários e os benefícios, diferenciando-se dos resultados dos outros anos. Isso leva-nos a questionar até que ponto a redução no número de empresas com a apreciação máxima em relação aos itens avaliados, altera o resultado final.

O novo item, a responsabilidade social, encontra-se em penúltimo lugar na avaliação dos sujeitos pesquisados, o que leva a questionar o papel dessas empresas em face do contexto brasileiro, uma vez que são empresas transnacionais. Finalmente, encontra-se reforçada na última pesquisa a tendência, verificada em 1999, de que a comunicação já foi mais clara e aberta entre aquelas que são as melhores para nelas se trabalhar.

Analisando-se os itens selecionados pelos pesquisadores como representativos das melhores práticas em recursos humanos nas organizações, constata-se que apresentam significativa similitude em relação ao modelo teórico de qualidade de vida no trabalho proposto por Walton (1973). Não estão adequadamente contemplados os fatores referentes à possibilidade de uso e desenvolvimento das capacidades e o espaço ocupado pelo trabalho no total da vida. Considera-se que em uma pesquisa futura tais fatores deveriam estar incluídos, pois em investigação desenvolvida por Tolfo (1995) em empresa estatal do Estado de Santa Catarina, 
o item considerado mais representativo da qualidade de vida no trabalho dos empregados da empresa se referia à oportunidade imediata de utilizar e desenvolver as capacidades humanas.

Quando são avaliadas as principais vantagens oferecidas pelas empresas, encontra-se um rol que vai ao encontro das tendências atuais no mundo do trabalho. No ano de 1997 destacavam-se: descentralização da gestão, premiação pelos resultados, comunicação aberta, ambiente agradável para trabalhar. Em contrapartida, há outras vantagens assinaladas que vêm sendo perdidas pelos empregados, como emprego estável e ampla oportunidade de ascensão profissional, ou ainda não são práticas usualmente adotadas pelas organizações, como possibilidade de o funcionário tornar-se sócio ou dono da empresa, excelente sistema de remuneração e exportação de talentos para outras subsidiárias do mundo.

Em 1999 persistiram algumas das vantagens apresentadas anteriormente: possibilidade de o empregado tornar-se sócio da empresa; premiação da superação das metas; ótimo ambiente de trabalho; oportunidade de crescimento profissional e carreira; salários do topo do mercado. Além destas, somam-se o ambiente que favorece a aprendizagem, o treinamento extensivo a todos os empregados, com universidade para tanto, a preocupação com a saúde dos empregados, o estímulo à lealdade, a boa comunicação e informalidade na relação chefia/empregado, a carreira baseada no mérito, o financiamento da moradia e a autonomia para o desenvolvimento do trabalho.

No presente ano, verifica-se o predomínio de aspectos relacionados à qualidade de vida, qualificação e as pessoas como centro do negócio.

O número de empresas que têm recebido avaliação máxima em relação a um maior número de itens avaliados foi sendo reduzido. Enquanto no ano de 1997, havia uma empresa com pontuação 5 em relação a sete dos oito itens avaliados, nos anos seguintes as empresas top alcançaram um máximo de seis itens mais bem avaliados. Mesmo assim, aumentou o quadro daquelas que se diferenciam em relação a quatro (1999) e a três itens (2000).

Fleury e Fischer (1992) salientaram, há vários anos, a ocorrência de alterações significativas nas políticas de recursos humanos, sendo que as temáticas da qualificação, da estabilização e do comprometimento formariam o eixo central dos padrões de relações de trabalho. A administração de recursos humanos no Brasil estaria passando por fase de transição, em que os modelos adotados até aqui não se mostram mais adequados, ao passo que os emergentes não estão suficientemente elaborados. Para as mesmas autoras, as mudanças mostram-se como desafio em razão das tendências conservadoras de grande parte dos empresários, dos dirigentes e dos profissionais de recursos humanos e das instabilidades 
geradas por crises conjunturais, levando à insegurança quanto a inovações que possam significar riscos às expectativas de rentabilidade.

Ao se utilizar como referencial as políticas de recursos humanos emergentes, que foram sistematizadas por Albuquerque e França (1998), considera-se que as empresas têm buscado atrair os empregados por este elenco: recompensas econômicas conjugadas com recompensas simbólicas; oportunidade de promoções; autonomia controlada; substituição dos mecanismos clássicos de controle pela confiança; tendência em eliminar o papel autoritário da hierarquia; intelectualização das tarefas; novas formas de gerenciamento científico das pessoas.

Cabe ressaltar ainda uma prática adotada pela empresa com melhor avaliação por parte dos funcionários e que foi denominada pelos pesquisadores como paternalismo explícito. Conforme os dados, é possível inferir que os empregados da Fiat brasileira se identificam com uma dimensão cultural, que é tanto brasileira quanto italiana, e que é tratada por Colbari (1996, p. 214-5):

"o paternalismo foi um componente importante na construção ideológica do mundo do trabalho na transição para o capitalismo industrial. [...] sobreviveu como estratégia efetiva de controle e como ideologia. Nesse caso fornece um repertório de valores e símbolos para um modelo de ordem social que opera a identificação do patrão com a figura do pai, responsável pela manutenção da empresa (família) e pelo sustento material e moral de seus operários (filhos). A contrapartida é fácil de ser deduzida: os operários (filhos) devem obediência e respeito ao patrão (pai) e dedicação e responsabilidade com a empresa (casa, família)".

Os resultados positivos de pesquisas que avaliam a qualidade de vida no trabalho, especialmente no Brasil, têm sido fonte de desconfiança por parte de estudiosos mais críticos. Concebida na sociedade americana, preocupada com as condições de trabalho e seus reflexos sobre o bem-estar do trabalhador, encontra um contexto social muito diferenciado nos países em desenvolvimento ou subdesenvolvidos. Isso pode ser vislumbrado a partir dos resultados da presente análise (1997), em que foram selecionadas inicialmente 4.000 empresas com mais de 300 funcionários, mas somente 11 delas receberam avaliação máxima em relação à metade ou mais dos itens considerados essenciais para que uma empresa seja considerada como excelente lugar para trabalhar. Pode inferir-se, então, que é muito reduzido o número de empresas brasileiras que efetivamente põem em prática ações que visem à qualidade de vida no trabalho do seu pessoal.

Neste sentido, concorda-se com Drucker (1995, p. 51), quando assinala que "hoje todas as organizações dizem: 'As pessoas são o nosso maior ativo'. Entretanto poucas praticam aquilo que pregam e menos ainda acreditam nisso. A mai- 
oria ainda acredita, embora talvez não conscientemente, naquilo que acreditavam os empregadores do século XIX: as pessoas precisam mais de nós do que nós delas".

E o contexto não está mudando no sentido de transformar esse estado de coisas, porque, conforme Bresciani (1997), existem contingências que alteram e aprofundam determinadas características do mundo do trabalho e da sua flexibilidade, como as seguintes:

. Aumento do contingente de trabalhadores autônomos e sem registro profissional.

- Crescimento do desemprego, pressionando os empregados à precarização das condições de trabalho.

- Aumento da jornada de trabalho ( $40 \%$ dos trabalhadores de quatro metrópoles brasileiras trabalharam além da jornada legal nos primeiros meses de 1996).

- Medida provisória sobre a desindexação permite que a reposição de perdas salariais deixem de ser automáticas.

. Elevadas taxas de turnover.

Aspectos como esses levam a inferir que a qualidade de vida no trabalho passa a ser aquela que é ofertada pela empresa, pois se torna melhor valorizar aquilo que se tem, do que fazer parte do exército de marginalizados, excluídos do mercado de trabalho.

\section{Conclusões}

O mundo do trabalho vem passando por profundas transformações; entretanto os reais impactos de tais mudanças sobre a organização do trabalho e sobre os trabalhadores, muitas vezes, não são suficientemente analisados, tanto teórica quanto empiricamente.

Existe um arcabouço teórico desenvolvido nos Estados Unidos, voltado para a humanização do trabalho, às condições adequadas à sua realização e à possibilidade de os empregados desenvolverem habilidades por meio das suas atividades laborais. Essa abordagem, que veio a ser identificada como qualidade de vida no trabalho, vem sendo desenvolvida desde a década de 50. Nesse período, foram propostos diversos modelos para o seu estudo e para a sua aplicação. Isso possibilitou uma onda de utilização dos métodos de QVT nas mais diversas empresas e países, incluindo o Brasil. 
Como não existe paradigma amplamente aceito sobre QVT, começaram a ser realizadas as mais diversas atividades, das mais simples e isoladas aos programas de qualidade de vida no trabalho, sob a égide de tal abordagem.

Os dados apresentados e discutidos neste trabalho trazem elementos de grande relevância, devido à inexistência de mais pesquisas que contemplem as práticas de recursos humanos nas empresas e como elas estão trabalhando no sentido de promover a qualidade de vida dos seus empregados. Embora possa questionar-se a metodologia e a sua aplicação por empresas de consultoria e com fins editoriais, representa o estudo mais abrangente de que se tem conhecimento.

Analisando-se os resultados, verificou-se, em primeiro lugar, significativa similaridade entre os itens definidos como essenciais para que uma empresa seja local excelente para trabalhar e o modelo de Walton (1973) sobre qualidade de vida no trabalho. Constata-se, mais uma vez, que a amplitude dos indicadores e das suas respectivas dimensões, propostas pelo autor, possibilitam uma visão abrangente da questão. Foi incluído um item referente à inovação no trabalho (1997 e 1999), o que condiz com o momento de mudanças no mundo do trabalho e vai ao encontro do que Walton (1973) salientou: a possibilidade de se incluir novos fatores, em decorrência do contexto.

Ao se observar os itens que caracterizam as empresas como bons lugares para trabalhar, encontra-se similaridade nos resultados referentes aos anos de $1997 \mathrm{e}$ 1999. O orgulho do trabalho e da empresa é citado como o mais representativo das melhores empresas, enquanto salários e benefícios se mostram como os aspectos mais limitantes. Relacionando os resultados arrolados com a abordagem teórica, verifica-se que as organizações proporcionam qualidade de vida no trabalho em relação à relevância social da vida no trabalho, ao passo que a compensação nem sempre é considerada justa e adequada. No ano 2000, a oportunidade de carreira e treinamento foi mais valorizada, indicando a possibilidade de crescimento e desenvolvimento, ao passo que a clareza e abertura na comunicação foi o item menos encontrado nas organizações. Dessa forma, os dados demonstram que predominam nas empresas os aspectos relacionados a uma perspectiva sistêmica e que não apresenta reflexos diretos sobre as condições específicas de trabalho e de vida do empregado. A remuneração, que atende às necessidades individuais, aparece em último lugar; o uso e o desenvolvimento das capacidades e o espaço ocupado pelo trabalho no total da vida do indivíduo nem mesmo foram pesquisados. Seriam hipóteses dos próprios pesquisadores em relação aos resultados?

As principais vantagens oferecidas pelas empresas aos seus empregados vão ao encontro de tendências desejáveis no mundo do trabalho, como estas: descen- 
tralização da gestão, premiação pelos resultados, comunicação aberta, ambiente agradável para trabalhar, programas de qualidade de vida, a pessoa como centro, possibilidade de o funcionário tornar-se sócio ou dono da empresa. Há algumas vantagens citadas que vêm sendo perdidas pelo contingente geral de trabalhadores, como emprego estável e oportunidade de ascensão profissional, ou não são as práticas usualmente mais adotadas pelas organizações, como excelente sistema de remuneração e exportação de talentos para outras subsidiárias do mundo.

Após considerar os resultados como um todo, cabe ainda tecer algumas considerações. Constata-se que foi selecionado nos anos de 1997, 1998, 1999 e 2000 um número de, respectivamente, 130, 208, 242 e 900 empresas brasileiras. Nesse mesmo intervalo, somente 30,50,50 e 100 delas passaram a fazer parte do rol de melhores empresas para nelas se trabalhar. Dessas empresas, quando avaliados os itens considerados essenciais para que elas sejam um local excelente para trabalhar, verificou-se uma tendência à redução do número de empresas e itens bem avaliados. Se pensarmos no contingente de organizações desclassificadas e na avaliação das empresas top, torna-se visível que a qualidade de vida no trabalho não pode ser considerada uma core competion das organizações brasileiras.

Existe um discurso formal que preconiza a importância dos recursos humanos para as organizações, mas a prática pouco reflete o encaminhamento nessa direção ${ }^{(3)}$. Conforme assinala Aktouf (1996), as mudanças no mundo do trabalho e as novas formas de organizá-lo escondem o fato de que continuam a tratar o ser humano como custo e como recurso.

\section{Notas}

${ }^{1}$ Foram analisados dados secundários divulgados pelas pesquisas. $\mathrm{O}$ artigo original foi apresentado no XXII ENANPAD, sendo sugerido que para essa publicação se fizesse uma comparação com os dados de 1999. Como no fechamento do artigo já havia sido lançada a revista Exame do ano de 2000, decidiu-se incluir também resultados mais atuais.

${ }^{2}$ O Great Place to Work é o principal articulador dessas pesquisas desde o primeiro guia, sendo responsável pela metodologia, elaboração dos questionários e tabulação dos dados. Outras consultorias participaram do projeto, como o Grupo Hay e jornalistas da própria Editora Abril.

${ }^{3}$ Volta-se a lembrar que foram trabalhados dados resultantes de pesquisas de que não se participou diretamente e precisa-se relativizá-los, pois os objetivos dos seus autores eram diferentes do pretendido na presente análise. 


\section{ReferênCIAS Bibliográficas}

AKTOUF, O.

A administração entre a tradição e a renovação. São Paulo : Atlas, 1996.

ALBUQUERQUE, L. G.;

FRANÇA, A. C. L.

Estratégias de recursos humanos e gestão da qualidade de vida no trabalho : o stress e a expansão do conceito de qualidade total. Revista de Administração, v. 33, n. 2, p. 40-51, abr./jun. 1998.

\section{BASTOS, A. V.}

Mudanças organizacionais e comprometimento com o trabalho. In: XXVI CONGRESSO INTERAMERICANO DE PSICOLOGIA (1997 : São Paulo). Caderno de Resumos... [S.1. : s.n.], 1997.

BOWDITCH, J. L.;

BUONO, A. F.

Elementos do comportamento organizacional. São Paulo : Pioneira, 1992.

\section{BRESCIANI, L. P.}

Flexibilidade e reestruturação : o trabalho na encruzilhada. São Paulo em Perspectiva, v. 11, $\mathrm{n}$. 1, p. 88-97, jan./mar. 1997.
COLBARI, A L.

Imagens familiares na cultura das organizações. In: DAVEL, E.; VASCONCELOS, J. Recursos humanos e subjetividade. Petrópolis : Vozes, 1996.

\section{EXAME.}

Guia das melhores empresas do Brasil para você trabalhar. [S.1.: s.n.], n. 647, 1997.

As melhores empresas para você trabalhar. [S.1.: s.n.], n. 695, 1999.

As 100 melhores empresas para você trabalhar. [S.1.: s.n.], n. 721, 2000.

FERNANDES, E.;

BECKER, J. L.

Qualidade de vida no trabalho : a realidade dos CPD's. In: XII REUNIÃO ANUAL DA ANPAD (1988 : Natal). Anais... Natal : ANPAD, 1988. v. 3. p. 1775-92.

FERNANDES, E. C.

Qualidade de vida no trabalho: como medir para melhorar. Salvador: Casa da Qualidade, 1996. 
FLEURY, M. T.;

FISCHER, R. M.

Relações de trabalho e políticas de gestão : uma história das questões atuais. Revista de Administração de Empresas, v. 27, n. 4, p. 5-15, out./dez. 1992.

HACKMAN, J. R.;

WAGEMAN, R.

Total quality management : empirical, conceptual, and pratical issues. Administrative Science Quarterly, n. 40, p. 309-342, June 1995.

RUAS, R.

Reestruturação sócio-econômica, adaptação das empresas e gestão do trabalho. In: GITAHY, L. (Org.). Reestructuración productiva, trabajo y educación en América Latina. Buenos Aires: RED-CENEP, 1994.
SILVA, N.;

TOLFO, S. R.

Cultura organizacional e qualidade de vida no trabalho : um estudo no ramo hoteleiro de Florianópolis. Departamento de Psicologia, Universidade Federal de Santa Catarina, set. 1995. projeto de pesquisa.

TOLFO, S. R.

Qualidade de vida no trabalho: o estudo do caso de uma empresa estatal. Departamento de Psicologia, Universidade Federal de Santa Catarina, 1995. relatório de pesquisa.

VOCÊ.

As 100 melhores empresas para você trabalhar. [S.l.: s.n.], n. $26,2000$.

WALTON, R. E.

Quality of working life : what is it? Sloan Management, v. 15, $\mathrm{n}$. 1, p. 11-21, 1973. 